\title{
Is adult height related to the risk of having Chronic Obstructive Pulmonary Disease (COPD)?
}

Katie Ward - Medical Student - University of Nottingham

Richard Hubbard - Professor of Respiratory Epidemiology

All Authors from the Division of Epidemiology and Public Health, University of Nottingham and work attributed to this department.

Address for correspondence: Professor Richard Hubbard, Respiratory Medicine,

Respiratory BRU, Clinical Sciences Building, City Hospital,

Hucknall Road, Nottingham NG5 1PB, England.

Telephone number: (44) 1158231709

Facsimile number: (44) 1158404771

Email: Richard.Hubbard@Nottingham.ac.uk

Sources of Funding: British Lung Foundation

Conflict of interest - none

Word count (excluding tables, contributions, references and abstract): 2575

Key words: Chronic Obstructive Pulmonary Disease, Epidemiology, Early Life Events, Adult Height

The Corresponding Author has the right to grant on behalf of all authors and does grant on behalf of all authors, an exclusive licence (or non-exclusive for government employees) on a worldwide basis to the BMJ Publishing Group Ltd and its Licensees to permit this article (if accepted) to be published in Journal of Epidemiology and Community Health and any other BMJPGL products to exploit all subsidiary rights, as set out in our licence (http://iech.bmi.com/ifora/licence.pdf). 


\section{What is already known on this subject?}

Adult height is inversely related to the risk of developing a number diseases and this association is presumed to reflect the impact of adverse living conditions in childhood. In historical studies the relationship between adult height and the risk of developing COPD has been particularly strong but what is not know is whether this effect still remains today now that living conditions have improved.

\section{What this study adds?}

In a cross-sectional study using computerized general practice records for more than a million adults we have demonstrated that adult height remains strongly associated to the risk of having COPD, and that this association was most marked in younger adults and decreased in strength with increasing age. Our findings suggest that socio-economic factors in early life remain important in the aetiology of COPD. 


\section{Abstract (words 250)}

Background: A number of historical studies have suggested that early life deprivation increases the risk of developing COPD in adult life, but whether this is still true now that living conditions have improved is not known. The aim of this study is to quantify the current association between adult height (a maker of socioeconomic status in early life) and COPD, and to determine how this varies by age.

Methods: We obtained data on 1,204,110 people (aged over 35yrs old) from The Health Improvement Network - a general practice database. We used a cross-sectional analysis to quantify the odds of having doctor diagnosed COPD in relation to height using logistic regression.

Results: In our dataset we had information on adult height for 1,025,662 (85\%) people and of these $2.7 \%$ had a diagnosis of COPD. The risk of having COPD decreased with each increase in quintile of height - odds ratio 0.90 (95\% confidence interval 0.89 to 0.91 ). There was evidence of effect modification by age group such that this association was strongest in people aged 35 to 49 years (odds ratio $0.86,95 \%$ confidence interval 0.82 to 0.89 ) and decreased progressively with age.

Conclusions: The risk of developing COPD is still strongly associated with adult height. This association is strongest in the youngest age category suggesting that early life experience will remain an important risk factor for COPD for some time to come and possibly that COPD related to early life deprivation is more severe and tends to present at a younger age. 


\section{Introduction (267 words)}

Although cigarette smoking remains the most important risk factor for developing COPD there are other risk factors, particularly socioeconomic deprivation which may exert its effect both in adulthood and during early life. ${ }^{1-4 ; 5}$ Adult height is influenced by socioeconomic status in childhood and so has been used by epidemiologists to determine whether socioeconomic deprivation early in life is a risk factor for adult disease ${ }^{6-8}$ In previous studies of adult height and disease specific mortality the associations with respiratory disease have generally been amongst the strongest. ${ }^{6 ; 8 ; 9}$ For example in an analysis of the Renfrew and Paisley cohort the rate ratio per quintile of adult height for mortality from respiratory disease was 1.35 for males, whilst that for stoke was 1.30 and that for cardiovascular disease was $1.12 .{ }^{8}$ Similarly in an analysis of the Whitehall 1 dataset Leon et al found that for each 6 inches decrease in height the risk of dying from COPD increased 1.58 times the equivalent figure for coronary heart disease was $1.27 .^{6}$

As socioeconomic conditions have improved in the UK there is evidence that height is increasing and that the influence of a number of early life factors on height, such as social class, maternal education and crowding, are becoming less marked. ${ }^{7}$ This raises the possibility that the early life influences on the risk of developing COPD may be becoming less important.

In order to investigate this question we have used a computerised general practice database to quantify the current relationship between adult height and the risk of having COPD and have stratified our results by age group, sex and adult socioeconomic status. 


\section{Methods (600 words)}

The Health Improvement Network (THIN) is a large computer database of anonymous medical records that have been collected and entered by primary care practitioners and staff as part of routine clinical care using the VISION software package (In Practice Systems) since $1987 .{ }^{10}$ The dataset includes information on participants demographic as well as their healthcare - including all diagnoses recorded by the general practitioner and also prescriptions issued. In addition general practitioners routinely code and enter data from other sectors of the health care system particularly clinic letters and discharge summaries from secondary care. For this study the dataset used was part of a larger programme of research into COPD and this work included an assessment of the impact of the NICE guidelines. ${ }^{2}$ For this reason the dataset was extracted to reflect the prevalence of COPD on 25/02/05, exactly one year after new NICE guidelines for COPD were published, and practices were excluded if they were not also providing data for THIN on 25/02/2003 - one year before the NICE guidelines. The study design for this study is therefore cross-sectional.

At the time our dataset was extracted there were about 2.3 million people alive and contributing data to THIN on 25/02/05. We excluded people under the age of 35 years because a diagnosis of COPD is discouraged in this age group. ${ }^{11}$ We only included people in our analysis if they had a recorded height and for this reason our dataset was restricted to 1,025,662 participants ( $85 \%$ of the initial total of $1,204,110)$. People were defined as having COPD if they had a medical code for COPD recorded anywhere in their medical records prior to the $25 / 02 / 05$. The list of medical codes we used for this were identical to those used for the Quality Outcomes Framework - which is in turn used to reimburse general practitioners for certain aspects of clinical care for people with COPD. We have previously shown that $62 \%$ of people with a clinical diagnosis of COPD in THIN have spirometry data in their records, and where present these data are strongly predictive of mortality suggesting that they are valid. ${ }^{2}$ 
We recorded age (in years) on 25/02/05 into the following categories: 35-49, 50-59, 60-69, 70-79, $80-89$ and greater than or equal to 90 years. Townsend scores based on 2001 census output areas were used as the measure of current adult social class, and these were available in THIN as quintiles. The majority of people with missing Townsend scores were living in Scotland reflecting differences in collection of census data. Adult Height was measured to the nearest centimetre and if there were multiple measurements, the mean was taken. We then divided adult height into quintiles separately for men and women using the xtile command in Stata.

Initially we used linear regression to calculate the mean height difference between people with and without a diagnosis of COPD, adjusting for age group, sex and Townsend score. We then used logistic regression to calculate the odds ratios for having COPD with each increasing quintile of height, adjusting for sex, age group and Townsend score. We analysed quintile of height first as a categorical variable and then as a continuous variable. We used multiplicative interaction terms to look for evidence of effect modification by sex, age group and Townsend score and also calculated the stratum specific odds ratios for the association between COPD and increasing quintile of height. All data analysis was carried out in Stata version 10 and likelihood ratio tests were used for hypothesis tests.

The study protocol for the programme of research on COPD was reviewed and approved by Nottingham Ethics Committee 1. 


\section{Results (320 words)}

Our study population consisted of $1,025,662$ people, of whom 28,374 (2.77\%) had a diagnosis of COPD recorded at some point in their records before 25/02/05 (Table 1). The total population had a slightly higher proportion of women than men, but a higher proportion of the people diagnosed with COPD were men (52.1\%). Younger people were less likely to have been diagnosed with COPD than older people. The prevalence of COPD increased markedly with increasing social deprivation. The mean height of men in our total population was $175.8 \mathrm{~cm}$ and that for women was $161.7 \mathrm{~cm}$. Overall mean height decreased with increasing age group and with increasing levels of socioeconomic disadvantage.

The results of our linear regression analysis showed that after adjusting for sex, age group and Townsend score the average height difference between people with and without COPD was $1.12 \mathrm{~cm}$. The size of this difference was similar when men $(1.09 \mathrm{~cm})$ and women $(1.10 \mathrm{~cm})$ were analysed separately. When we divided people into quintiles of height the approximate difference in height between quintile was $4 \mathrm{~cm}$ for men and women (Table 2 ).

The results of our logistic regression showed that the risk of having COPD increased with being male, older age and socioeconomic disadvantage (Table 3). There was a strong dose related association between increasing height and a reduced risk of having COPD that persisted after adjusting for age group, sex and socioeconomic status. In our fully adjusted model people in the tallest quintile had a $39 \%$ reduction in the odds of having COPD compared to people in the shortest quintile. Our tests for interaction and stratified results showed that the association between height and the risk of having COPD was similar for males and females but was strongest in the youngest age groups and decreased in strength with increasing age group (Table 4). Although there was a strongly statistically significant interaction between Townsend score and height there was no clear trend across the strata. 


\section{Discussion (1377 words)}

The results of our study show that men and women who are taller have a reduced risk of being diagnosed with COPD. This difference was confounded by age and adult socioeconomic status but even after allowing for the effects of these variables for every increase in quintile of height (approximately $4 \mathrm{~cm}$ ) there was a 10\% reduction in the odds of having COPD. We found evidence of effect modification by age group such that the association between COPD and height was most marked in the youngest age group and decreased progressively with increasing age. Our findings add to the previous literature that a shorter adult height is a risk factor for having COPD and demonstrate that early life experience is still an important risk factor for COPD and will remain so for some time to come.

\section{Strengths and weaknesses}

The main strengths of our study are the large and contemporary nature of the dataset which allowed us to produce up to date results and to stratify our results by age and an adult marker of socioeconomic status. An additional benefit is the completeness of the data on height with a value available for more than $85 \%$ of people over the age of 35 years in THIN. The main potential weaknesses of our dataset that need consideration are the validity of the data on height and the validity of diagnoses of COPD. The average heights for men and women that we found in our study (175.8cm for men and $161.7 \mathrm{~cm}$ for women) are remarkably similar to the figures reported from the 2005 Health Survey for England (175.3cm for men and $161.4 \mathrm{~cm}$ for women - www.ic.nhs.uk) suggesting that overall our data are valid. It seems likely to us that information on height recorded in general practice records will come from a variety of sources and be collected in a variety of settings and this means that a degree of random error is inevitable. This means that if anything we will have underestimated the true association between COPD and decreased adult height. We were not able to validate the diagnoses of COPD recorded in THIN directly, but as we have discussed before in terms of prevalence of the condition and the age, sex, smoking habit and survival of people with the 
diagnosis the data appear appropriate. ${ }^{2}$ Furthermore since COPD is a diagnosis that general practitioners are very familiar with we believe that the specificity of this diagnosis will be high, in other words most of the people with a diagnosis of COPD will have that condition. It seems likely that the sensitivity of the COPD diagnoses will be less good and that there will be a significant number of people with COPD in whom the diagnosis has not been made or recorded. For example in a study using the Third National Health and Nutrition Examination Survey (NHANESIII) Coultas et al found that doctor diagnosed COPD had a prevalence of $3.1 \%$ in adults over the age of 45 years, but when using lung function criteria based on the lower limit of normal this prevalence increased to $12 \% .{ }^{12}$ In this study the people with undiagnosed COPD tended to have milder disease than those with a doctor diagnosis both in terms of lung function impairment and symptoms. The implication for our study is that the people we have defined as having COPD are likely to represent the more severe end of the disease spectrum, and that a number of people with milder undiagnosed COPD will be included with the non-COPD group. This in turns means that if adult height is a risk factor for having COPD but does not influence the severity of disease that we may have underestimated the true association between adult height and COPD. On the other had if adult height also predicts the severity of COPD we may have over-estimated the strength of its association with COPD.

\section{Comparison to other studies and possible explanations for findings}

Although the literature on adult height and COPD is much smaller than that for cardiovascular disease there have been a few previous studies. In general these studies have focused on the mortality follow-up of large cohorts. As mentioned in the introduction analyses of the Whitehall cohort and the Renfrew and Paisley cohort both found an inverse association between adult height and death from respiratory disease. In order to compare our figures directly with those from the Whitehall study we have estimated the odds ratio for having COPD for each decrease in height of 6 inches $(15.24 \mathrm{~cm})$ and found this to be 1.43 (95\% confidence interval 1.39 to 1.47$)$ and this figure is similar to the Hazard ratio of 1.58 reported for the increased risk of dying from COPD for the same 
decrease in height. Similar findings have also been reported from cohorts in Korea $a^{9 ; 13}$ and Finland ${ }^{14}$. In general the associations between height and death from COPD and/or respiratory disease have been greater in magnitude than those seen for all cause mortality and cardiovascular disease. Our current study is that first study that we are aware of to demonstrate an association between adult height and risk of COPD in living people, and also the first of sufficient size to be able to stratify the data by age groups.

Our hypothesis is that factors related to socioeconomic disadvantage early in life lead to both decreased growth and an increased risk of COPD in later life but there are other possible explanations for our data. The first is reverse causation, i.e. that COPD leads to a decrease in height rather than the other way around. This alternative explanation was suggested by Leon et $\mathrm{al}^{6}$ with the development of kyphosis as a consequence of corticosteroid use being a possible mechanism. This seems unlikely to us for two reasons. Firstly the difference in height between people with and without COPD was greatest in the youngest age group and decreased progressively with age. If COPD causes "shrinkage" we would expect this association to be the other way around as in general older people have had COPD for longer. Secondly in the general practice population the use of oral corticosteroids is actually quite low as most people have mild disease. ${ }^{15}$

Another possible explanation for our findings is that people who are shorter have smaller lungs in the first place and so shorter people with COPD may be more likely to present than taller people with COPD, and may also tend to present at a younger age. This would be the case if respiratory symptoms were more closely related to absolute lung volumes rather than percent predicted values which take account of height, age and sex. The data available in this area are limited but the one study available suggests symptoms are actually more strongly related to percent predicted values than absolute values so again this alternative explanation seems unlikely to us. ${ }^{16}$ 
In our study the association between adult height and the risk of having COPD was most marked in the youngest age category and the reasons for this are not clear. If the relationship between height and risk of COPD simply reflected an impact of early life socioeconomic disadvantage we would have expected the difference in height to be greatest in the oldest age category because social conditions in the UK have improved progressively over the last fifty years. There are a number of potential explanations for our findings. The first is survival bias arising from the cross-sectional nature of our study design. If COPD associated with early life deprivation and reduced stature is particularly severe then these people may present and die at a younger age and so be under represented in the older categories in our cross-sectional study. The second explanation is that although the social factors such as housing have improved progressively in the UK over the last fifty years the ones most relevant to COPD have not. Further longitudinal analyses of the age categories in our dataset will be needed to determine which of these explanations is correct. ${ }^{7 ; 17}$

\section{Clinical implications}

Although there can be no doubt that social factors have improved in the UK over the last fifty years the results of our study suggest that early life socioeconomic disadvantage still has an important influence on the risk of developing COPD in the UK, particularly in younger adults.

\section{Author Contributions}

The original idea for the study came from RH. KW did all of the data management and analysis under the supervision of RH as part of her BMedSci degree at the University of Notitngham. KW led on the writing of the paper but RH was responsible for the final editing of the paper. 
Table 1 - Characteristics of people in the study according to the presence or absence of COPD

\begin{tabular}{|c|c|c|c|c|}
\hline & \multicolumn{2}{|c|}{ People without COPD } & \multicolumn{2}{|c|}{ People with COPD } \\
\hline & Number of People (\%) & Mean Height /cm (SD) & Number of People (\%) & Mean Height /cm (SD) \\
\hline Total & 997,288 & $168.3(10.0)$ & 28,374 & $166.2(9.8)$ \\
\hline Males & 461,132 (46.2) & $175.9(7.2)$ & $14,789(52.1)$ & $172.8(7.1)$ \\
\hline Females & $536,156(53.7)$ & $161.8(6.9)$ & $13,585(47.9)$ & $159.0(6.7)$ \\
\hline \multicolumn{5}{|l|}{ Age group } \\
\hline 35 to 49.9 & 387,629 (38.9) & $169.8(9.9)$ & $1,213(4.3)$ & $167.4(10.0)$ \\
\hline 50 to 59.9 & $228,227(22.9)$ & $168.8(9.8)$ & $3,747(13.2)$ & $167.1(9.9)$ \\
\hline 60 to 69.9 & $179,185(18.0)$ & $168.0(9.6)$ & $7,988(28.2)$ & $167.2(9.5)$ \\
\hline 70 to 79.9 & $126,450(12.7)$ & $166.2(9.6)$ & $9,537(33.6)$ & $166.2(9.6)$ \\
\hline 80 to 89.9 & $64,409(6.5)$ & $163.5(9.5)$ & $5,260(18.5)$ & $164.3(9.6)$ \\
\hline 90 and over & $11,388(1.1)$ & $160.0(9.4)$ & $629(2.2)$ & $161.4(10.5)$ \\
\hline \multicolumn{5}{|l|}{ Quintile of Townsend Score } \\
\hline 1 & $231,035(23.2)$ & $169.2(9.8)$ & $3,610(12.7)$ & $167.9(9.9)$ \\
\hline 2 & $193,481(19.4)$ & $168.7(9.8)$ & $3,986(14.0)$ & $167.4(9.6)$ \\
\hline 3 & $171,667(17.2)$ & $168.1(9.9)$ & $4,814(17.0)$ & $166.2(9.7)$ \\
\hline 4 & $135,438(13.6)$ & $167.5(10.0)$ & $5,596(19.7)$ & $165.6(9.7)$ \\
\hline 5 (most disadvantaged) & $88,967(8.9)$ & $166.9(10.1)$ & $5,209(18.4)$ & $164.9(9.6)$ \\
\hline Missing & $176,700(17.7)$ & $168.2(10.1)$ & $5,159(18.2)$ & $166.2(9.9)$ \\
\hline
\end{tabular}


Table 2 - quintiles of height for men and women

\begin{tabular}{|ccccc|}
\hline Quintile of height $(\mathrm{cm})$ & \multicolumn{2}{c|}{ Females } & \multicolumn{2}{c|}{ nales } \\
& number & height $(\mathrm{cm})$ & 105,787 & height $(\mathrm{cm})$ \\
1 & 114,664 & $<156.0$ & 91,577 & 170.0 \\
2 & 129,782 & 156.0 to 160.0 & 174.0 \\
3 & 92,926 & 160.1 to 163.0 & 112,602 & 174.1 to 178.0 \\
4 & 102,421 & 163.1 to 167.8 & 75,075 & 178.1 to 182.0 \\
5 & 109,948 & $>167.8$ & 90,880 & $>182.0$ \\
\hline
\end{tabular}


Table 3 Odds ratios for the association between COPD and height and other co-variates

\begin{tabular}{|c|c|c|c|c|c|c|c|c|}
\hline \multirow{3}{*}{$\begin{array}{l}\text { Female } \\
\text { Male }\end{array}$} & \multicolumn{4}{|c|}{ Univariate analysis } & \multicolumn{4}{|c|}{ Multivariate analysis* } \\
\hline & $\begin{array}{c}\text { Odds ratio } \\
1.00\end{array}$ & \multicolumn{3}{|c|}{$95 \%$ confidence interval } & $\begin{array}{l}\text { Odds ratio } \\
1.00\end{array}$ & \multicolumn{3}{|c|}{$95 \%$ confidence interva } \\
\hline & 1.27 & 1.24 & to & 1.30 & 1.38 & 1.35 & to & 1.42 \\
\hline \multicolumn{9}{|l|}{ Age } \\
\hline 35 to 49.9 & 1.00 & & & & 1.00 & & & \\
\hline 50 to 59.9 & 5.25 & 4.92 & to & 5.60 & 5.33 & 4.99 & to & 5.69 \\
\hline 60 to 69.9 & 14.25 & 13.41 & to & 15.14 & 14.32 & 13.47 & to & 15.21 \\
\hline 70 to 79.9 & 24.10 & 22.70 & to & 25.59 & 23.29 & 21.92 & to & 24.74 \\
\hline 80 to 89.9 & 26.10 & 24.50 & to & 27.79 & 24.15 & 22.66 & to & 25.73 \\
\hline 90 and over & 17.65 & 16.00 & to & 19.47 & 16.09 & 14.57 & to & 17.77 \\
\hline \multicolumn{9}{|l|}{ Quintile of Townsend Score } \\
\hline 1 & 1.00 & & & & 1.00 & & & \\
\hline 2 & 1.32 & 1.26 & to & 1.38 & 1.25 & 1.19 & to & 1.31 \\
\hline 3 & 1.79 & 1.72 & to & 1.87 & 1.76 & 1.68 & to & 1.84 \\
\hline 4 & 2.64 & 2.53 & to & 2.76 & 2.57 & 2.46 & to & 2.68 \\
\hline 5 (most disadvantaged) & 3.75 & 3.59 & to & 3.91 & 3.68 & 3.52 & to & 3.85 \\
\hline Missing & 1.87 & 1.79 & to & 1.95 & 1.90 & 1.82 & to & 1.99 \\
\hline \multicolumn{9}{|l|}{ Quintile of height } \\
\hline 1 (shortest) & 1.00 & & & & 1.00 & & & \\
\hline 2 & 0.69 & 0.66 & to & 0.71 & 0.87 & 0.84 & to & 0.89 \\
\hline 3 & 0.55 & 0.53 & to & 0.57 & 0.77 & 0.75 & to & 0.80 \\
\hline 4 & 0.48 & 0.46 & to & 0.50 & 0.79 & 0.76 & to & 0.82 \\
\hline 5 & 0.30 & 0.29 & to & 0.31 & 0.61 & 0.58 & to & 0.63 \\
\hline Odds ratio per quintile of height & 0.76 & 0.75 & to & 0.76 & 0.90 & 0.89 & to & 0.91 \\
\hline
\end{tabular}

*mutually adjusted for all variables in the table 
Table 4: Odds ratios for COPD per quintile of height stratified by other covariates

\begin{tabular}{|c|c|c|c|c|c|}
\hline \multirow[b]{2}{*}{ Female } & \multirow{2}{*}{$\begin{array}{c}\text { Odds ratio* } \\
0.89\end{array}$} & \multicolumn{3}{|c|}{$95 \%$ confidence interval } & \multirow[t]{2}{*}{ Pinteraction } \\
\hline & & 0.88 & to & 0.91 & \\
\hline Male & 0.90 & 0.89 & to & 0.91 & 0.06 \\
\hline \multicolumn{6}{|l|}{ Age } \\
\hline 35 to 49.9 & 0.86 & 0.82 & to & 0.89 & \\
\hline 50 to 59.9 & 0.88 & 0.86 & to & 0.90 & \\
\hline 60 to 69.9 & 0.89 & 0.88 & to & 0.91 & \\
\hline 70 to 79.9 & 0.90 & 0.88 & to & 0.91 & \\
\hline 80 to 89.9 & 0.94 & 0.92 & to & 0.96 & \\
\hline 90 and over & 0.95 & 0.88 & to & 1.02 & $<0.0001$ \\
\hline \multicolumn{6}{|c|}{ Quintile of Townsend Score } \\
\hline 1 & 0.90 & 0.88 & to & 0.93 & \\
\hline 2 & 0.91 & 0.88 & to & 0.93 & \\
\hline 3 & 0.88 & 0.86 & to & 0.90 & \\
\hline 4 & 0.89 & 0.87 & to & 0.91 & \\
\hline 5 (most disadvantaged) & 0.92 & 0.90 & to & 0.94 & \\
\hline Missing & 0.89 & 0.87 & to & 0.91 & $<0.0001$ \\
\hline
\end{tabular}

* Mutually adjusted for the

other variables in the table 


\section{Reference List}

(1) Barker DJP, Godfrey KM, Fall CHD, Osmond C, Winter PD, Shaheen SO. Relation of birthweight and childhood respiratory infection to adult lung function and death from chronic obstructive lung disease. Br Med J 1991; 303:671-675.

(2) Smith CJ, Gribbin J, Challen KB, Hubbard RB. The impact of the 2004 NICE guideline and 2003 General Medical Services contract on COPD in primary care in the UK. QJM 2008.

(3) Mannino DM, Watt G, Hole D, Gillis C, Hart C, McConnachie A et al. The natural history of chronic obstructive pulmonary disease. Eur Respir J 2006; 27(3):627-643.

(4) Anto JM, Vermeire P, Vestbo J, Sunyer J. Epidemiology of chronic obstructive pulmonary disease. Eur Respir J 2001; 17(5):982-994.

(5) Strachan DP, Sheikh A. A life course approach to respiratory and allergic diseases. In: Kuh D, Ben-Shlomo Y, editors. A life course approach to chronic disease epidemiology. 2nd ed. Oxford: Oxford University Press; 2004. 240-258.

(6) Leon DA, Davey Smith G, Shipley M, Strachan D. Adult height and mortality in london: early life, socioeconomic confounding or shrinkage? Journal of Eidemiology and Community Health 49, 5-9. 1995.

Ref Type: Generic

(7) Li L, Power C. Influences on childhood height: comparing two generations in the 1958 British birth cohort. Int J Epidemiol 2004; 33(6):1320-1328.

(8) Davey SG, Hart C, Upton M, Hole D, Gillis C, Watt G et al. Height and risk of death among men and women: aetiological implications of associations with cardiorespiratory disease and cancer mortality. J Epidemiol Community Health 2000; 54(2):97-103.

(9) Song YM, Smith GD, Sung J. Adult height and cause-specific mortality: a large prospective study of South Korean men. Am J Epidemiol 2003; 158(5):479-485.

(10) Bourke A, Dattani H, Robinson M. Feasibility study and methodology to create a qualityevaluated database of primary care data. Inform Prim Care 2004; 12(3):171-177.

(11) British Thoracic Society. Chronic Obstructive Pulmonary Disease. National clinical guideline on management of chronic obstructive pulmonary disease in adults in primary and secondary care. Thorax 2004; 59(S1):s1-s232.

(12) Coultas DB, Mapel D, Gagnon R, Lydick E. The health impact of undiagnosed airflow obstruction in a national sample of United States adults. Am J Respir Crit Care Med 2001; 164(3):372-377.

(13) Song YM, Sung J. Adult height and the risk of mortality in South Korean women. Am J Epidemiol 2008; 168(5):497-505.

(14) Jousilahti P, Tuomilehto J, Vartiainen E, Eriksson J, Puska P. Relation of adult height to cause-specific and total mortality: a prospective follow-up study of 31,199 middle-aged men and women in Finland. Am J Epidemiol 2000; 151(11):1112-1120. 
(15) Pujades-Rodriguez M, Smith CJ, Hubbard RB. Inhaled corticosteroids and the risk of fracture in chronic obstructive pulmonary disease. QJM 2007; 100(8):509-517.

(16) Jakeways N, McKeever T, Lewis SA, Weiss ST, Britton J. Relationship between FEV1 reduction and respiratory symptoms in the general population. Eur Respir J 2003; 21(4):658663.

(17) Power C, Manor O, Li L. Are inequalities in height underestimated by adult social position? Effects of changing social structure and height selection in a cohort study. BMJ 2002; 325(7356):131-134. 